\title{
LSSVM-Based Rock Failure Criterion and Its Application in Numerical Simulation
}

\author{
Changxing Zhu, Hongbo Zhao, and Zhongliang Ru \\ School of Civil Engineering, Henan Polytechnic University, Jiaozuo 454003, China \\ Correspondence should be addressed to Hongbo Zhao; bxhbzhao@hotmail.com
}

Received 19 November 2014; Revised 3 February 2015; Accepted 11 February 2015

Academic Editor: Erik Cuevas

Copyright (C) 2015 Changxing Zhu et al. This is an open access article distributed under the Creative Commons Attribution License, which permits unrestricted use, distribution, and reproduction in any medium, provided the original work is properly cited.

A rock failure criterion is very important for the prediction of the failure of rocks or rock masses in rock mechanics and engineering. Least squares support vector machines (LSSVM) are a powerful tool for addressing complex nonlinear problems. This paper describes a LSSVM-based rock failure criterion for analyzing the deformation of a circular tunnel under different in situ stresses without assuming a function form. First, LSSVM was used to represent the nonlinear relationship between the mechanical properties of rock and the failure behavior of the rock in order to construct a rock failure criterion based on experimental data. Then, this was used in a hypothetical numerical analysis of a circular tunnel to analyze the mechanical behavior of the rock mass surrounding the tunnel. The Mohr-Coulomb and Hoek-Brown failure criteria were also used to analyze the same case, and the results were compared; these clearly indicate that LSSVM can be used to establish a rock failure criterion and to predict the failure of a rock mass during excavation of a circular tunnel.

\section{Introduction}

The failure of rock has been one of the most active research areas in the engineering of rock structures since the establishment of the International Society for Rock Mechanics (ISRM) in 1962. Ulusay and Hudson gave a detailed description of the importance of the ability to predict rock failure in practical engineering [1]. Rock failure criteria include the theoretical basis of methods of predicting when and how rock materials fail under the action of external loads and are therefore essential for optimization of engineering design and construction in rock masses. Over the past several decades, a number of failure criteria have been proposed (e.g., MohrCoulomb, Hoek-Brown, and Griffith's and Drucker-Prager criteria) and developed to predict the failure of rock [211]. Recently, ISRM suggested methods have been published as criteria for the prediction of rock failure [12, 13]. Both the Mohr-Coulomb and Hoek-Brown criteria are generally considered to be reliable predictors of rock failure. In these two models, the major principal stress $\sigma_{1}$ is seen as function of the uniaxial compressive strength $\left(\sigma_{c}\right)$, the minor principal stress $\left(\sigma_{3}\right)$, and some constants, that is, $f\left(\sigma_{1}, \sigma_{3}\right)=0$. These constants can often be determined by laboratory experiment, in situ tests, and back-analysis.

Empirical failure criteria established under specific conditions such as rock type, stress state, or functional form are not generic and cannot be adopted uncritically for any set of conditions [10] but must be established experimentally for any given set of rock formation and stress conditions.

For this reason, artificial neural network (ANN) computational models are widely used to establish rock failure criteria for geotechnical engineering problems. This is due to the fact that ANN perform function approximation without requiring additional assumptions of the function form. More detailed descriptions of the ANN-based failure criterion method have been reported by, for example, Meulenkamp and Grima, Singh et al., Çanakci and Pala, Tiryaki, Zorlu et al., and Rafiai and Jafari [14-20]. However, a disadvantage of ANN for establishing rock failure criteria is its slow convergence and overfitting. To overcome these limitations, 
in the present study a LSSVM-based rock failure criterion was developed based on experimental data. Support vector machines (SVM) have been widely used in geotechnical engineering for nonlinear mapping [21-23].

This paper is organized as follows. Section 2 focuses on the formulation of LSSVM. A LSSVM-based rock failure criterion is described in detail in Section 3. In Section 4, a hypothetical numerical experiment is used to verify the LSSVM-based rock failure criterion by comparing with earlier failure criteria. Finally, conclusions are given in Section 5.

\section{Least-Squares Support Vector Machine (LSSVM)}

LSSVM models are an alternative formulation of SVM regression proposed by Suykens and Vandewalle [24]. Suppose there is a given training set of $N$ data points $\left\{x_{k}, y_{k}\right\}(k=$ $1,2, \ldots, N)$ with input data $x_{k} \in R^{N}$ and output $y_{k} \in r$, where $R^{N}$ is an $N$-dimensional vector space and $r$ is a onedimensional vector space; LSSVM models in feature space are given by

$$
y(x)=w^{T} \phi(x)+b
$$

where the nonlinear mapping $\varphi(\cdot)$ represents the input data in a higher-dimensional feature space; $w \in R^{n} ; b \in r ; w$ is an adjustable weight vector; and $b$ is the scalar threshold. For function estimation in LSSVM, the following optimization problem is formulated:

$$
\begin{array}{ll}
\text { Minimize } & \frac{1}{2} w^{T} w+\gamma \frac{1}{2} \sum_{k=1}^{N} e_{k}^{2} \\
\text { Subjected to } & y(x)=w^{T} \varphi(x)+b+e_{k}, \quad k=1, \ldots, N,
\end{array}
$$

where $\gamma$ is the regularization parameter for determining the trade-off between the fitting error minimization and smoothness, and $e_{k}$ is an error variable.

The Lagrangian $(L(w, b, e, \alpha))$ for the above optimization problem (2) is

$$
\begin{aligned}
L(w, b, e ; \alpha)= & \frac{1}{2} w^{T} w+\gamma \frac{1}{2} \sum_{k=1}^{N} e_{k}^{2} \\
& -\sum_{k=1}^{N} \alpha_{k}\left\{y_{k}\left[w^{T} \varphi\left(x_{k}\right)+b\right]-1+e_{k}\right\},
\end{aligned}
$$

where $\alpha_{k}$ is the Lagrange multiplier. The conditions for optimality are given by

$$
\frac{\partial L}{\partial w}=0 \Longrightarrow w=\sum_{k=1}^{N} \alpha_{k} \varphi\left(x_{k}\right),
$$

$$
\begin{gathered}
\frac{\partial L}{\partial b}=0 \Longrightarrow \sum_{k=1}^{N} \alpha_{k}=0, \\
\frac{\partial L}{\partial e_{k}}=0 \Longrightarrow \alpha_{k}=\gamma e_{k}, \quad k=1, \ldots, N, \\
\frac{\partial L}{\partial \alpha_{k}}=0 \Longrightarrow w^{T} \varphi\left(x_{k}\right)+b+e_{k}-y_{k}=0, \quad k=1, \ldots, N
\end{gathered}
$$

without regard to $e_{k}$ and $w$; the solution is given by the following set of linear equations:

$$
\Phi\left[\begin{array}{l}
b \\
\alpha
\end{array}\right]=\left[\begin{array}{l}
0 \\
y
\end{array}\right]
$$

where $y=\left[y_{1}, \ldots, y_{N}\right], \mathbf{1}=[1, \ldots, 1], \alpha=\left[\alpha_{1}, \ldots, \alpha_{N}\right]$, and Mercer's theorem is applied within the $\Omega$ matrix, $\Omega=$ $\varphi\left(x_{k}\right)^{T} \varphi\left(x_{l}\right)=K\left(x_{k}, x_{l}\right), k, l=1, \ldots, N$, where $K\left(x_{k}, x_{l}\right)$ is the kernel function, and the matrix $\Phi$ is invertible by choosing $\gamma>w$ and can be written as

$$
\Phi=\left[\begin{array}{cc}
0 & 1^{T} \\
1 & \Omega+\gamma^{-1} I
\end{array}\right] .
$$

Then the analytical solution of $\alpha$ and $b$ is given by

$$
\left[\begin{array}{l}
b \\
\alpha
\end{array}\right]=\Phi^{-1}\left[\begin{array}{l}
0 \\
y
\end{array}\right]
$$

The LSSVM model can then be expressed as

$$
y(x)=\sum_{k=1}^{N} \alpha_{k} K\left(x, x_{k}\right)+b .
$$

In (8), $K\left(x, x_{k}\right)$ is the kernel function, composed of the following three forms.

(1) Polynomial kernel:

$$
K(X, Y)=((X \cdot Y)+1)^{d}, \quad d=1,2, \ldots, n .
$$

(2) Radial kernel:

$$
K(X, Y)=\exp \left\{-\frac{|X-Y|^{2}}{2 \sigma^{2}}\right\} .
$$

(3) Sigmoidal kernel:

$$
K(X, Y)=\tanh (\varphi(X \cdot Y)+\theta)
$$

The brief procedure LSSVM is the following.

Step 1. Build the training samples $\left(x_{k}, y_{k}\right)$ based on rock mechanical experiment.

Step 2. Get (6) according to the LSSVM algorithm.

Step 3. Get the analytical solution of $\alpha$ and $b$ in (7).

Step 4. Get the LSSVM model (8). 


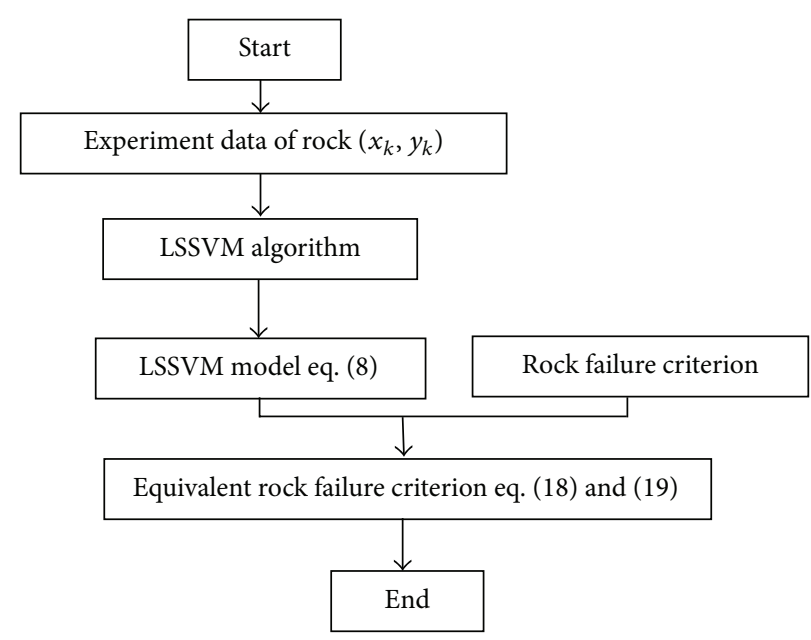

FIGURE 1: The flowchart of LSSVM-based failure criterion.

\section{LSSVM-Based Rock Failure Criteria}

In order to better predict the behavior failure of rock masses, LSSVM was used in this work to represent the nonlinear relationship between rock properties and rock failure and thus to establish a LSSVM-based rock failure criterion. Similar to traditional failure criteria in form, LSSVM-based rock failure criteria can be defined as

$$
\operatorname{SVM}\left(\sigma_{1}, \sigma_{3}\right)=0 \text {, }
$$

where $\sigma_{1}$ and $\sigma_{3}$ are the major and minor principal stresses, respectively. These can be obtained by laboratory experiment and field testing. The LSSVM-based rock failure criterion can be rewritten in the form:

$$
\sigma_{1}=\sum_{k=1}^{N} \alpha_{k} K\left(\sigma_{3}, \sigma_{3 k}\right)+b,
$$

where $\sigma_{3 k}$ is the series of experimental data and $\alpha_{k}$ and $b$ are calculated using the algorithm introduced in Section 2. Once a LSSVM-based rock failure criterion is established, it can be used in numerical analysis to predict rock failure. In this work, Excel VBA software was used to execute the code of the LSSVM-based rock failure criterion.

To implement the LSSVM-based failure criteria in a numerical model, it is useful to express it as an equivalent Mohr-Coulomb criterion with variable parameters. The parameters of the equivalent criterion are obtained as

$$
\begin{gathered}
\sigma_{c}^{\mathrm{eq}}=\sigma_{1}-q^{\mathrm{eq}} \sigma_{3}=\sum_{k=1}^{N} \alpha_{k} K\left(\sigma_{3}, \sigma_{3 k}\right)+b-q^{\mathrm{eq}} \sigma_{3}, \\
q^{\mathrm{eq}}=\frac{\partial \sigma_{1}}{\partial \sigma_{3}}=\frac{\partial\left(\sum_{k=1}^{N} \alpha_{k} K\left(\sigma_{3}, \sigma_{3 k}\right)\right)}{\partial \sigma_{3}}=\sum_{k=1}^{N} \alpha_{k} \frac{\partial\left(K\left(\sigma_{3}, \sigma_{3 k}\right)\right)}{\partial \sigma_{3}} .
\end{gathered}
$$

The RBF kernel function (Equation (10)) was adopted:

$$
\frac{\partial\left(K\left(\sigma_{3}, \sigma_{3 k}\right)\right)}{\partial \sigma_{3}}=-\frac{1}{\sigma^{2}} K\left(\sigma_{3}, \sigma_{3 k}\right) .
$$

Substituting (16) into (15) gives the following form:

$$
q^{\mathrm{eq}}=-\frac{1}{\sigma^{2}} \sum_{k=1}^{N} \alpha_{k} K\left(\sigma_{3}, \sigma_{3 k}\right)
$$

and the equivalent Mohr-Coulomb criterion may be calculated from the following equations:

$$
\begin{gathered}
c^{\mathrm{eq}}=\frac{\sigma_{c}^{\mathrm{eq}}}{2 \sqrt{q^{\mathrm{eq}}}}, \\
\varphi^{\mathrm{eq}}=2 \tan ^{-1}\left(\sqrt{q^{\mathrm{eq}}}\right)-\frac{\pi}{2},
\end{gathered}
$$

where $c^{\mathrm{eq}}$ and $\varphi^{\mathrm{eq}}$ are the instantaneous values of cohesion and friction angle, respectively.

LSSVM-based rock failure criterion presents the mechanical character of rock through combining L-SVM and rock failure criterion. The brief procedure is showed in Figure 1. 
TABLE 1: Experimental data and the values of Lagrange multiplier $\alpha_{k}$.

\begin{tabular}{|c|c|c|c|c|c|c|c|}
\hline Number & $\sigma_{3}(\mathrm{Mpa})$ & $\sigma_{1}(\mathrm{Mpa})$ & $\alpha_{k}$ & Number & $\sigma_{3}(\mathrm{Mpa})$ & $\sigma_{1}(\mathrm{Mpa})$ & $\alpha_{k}$ \\
\hline 1 & 0.0000 & 0.0000 & -138.4852 & 41 & 3.8699 & 17.8247 & 0.1287 \\
\hline 2 & 0.0853 & 2.7979 & 97.6169 & 42 & 3.9471 & 18.0397 & 0.0845 \\
\hline 3 & 0.2398 & 4.0913 & 5.5845 & 43 & 4.0244 & 18.2534 & 0.0837 \\
\hline 4 & 0.3170 & 4.6287 & 2.2133 & 44 & 4.1016 & 18.4657 & 0.0829 \\
\hline 5 & 0.3943 & 5.1224 & 1.6698 & 45 & 4.1788 & 18.6769 & 0.0822 \\
\hline 6 & 0.4715 & 5.5829 & 1.3160 & 46 & 4.2561 & 18.8868 & 0.1220 \\
\hline 7 & 0.5487 & 6.0173 & 1.5167 & 47 & 4.4105 & 19.3033 & 0.1210 \\
\hline 8 & 0.7032 & 6.8251 & 1.2040 & 48 & 4.4878 & 19.5098 & 0.0800 \\
\hline 9 & 0.7804 & 7.2046 & 0.6538 & 49 & 4.5650 & 19.7153 & 0.1193 \\
\hline 10 & 0.8577 & 7.5708 & 0.5713 & 50 & 4.7195 & 20.1231 & 0.1186 \\
\hline 11 & 0.9349 & 7.9254 & 0.7297 & 51 & 4.7967 & 20.3255 & 0.0787 \\
\hline 12 & 1.0894 & 8.6045 & 0.6295 & 52 & 4.8740 & 20.5269 & 0.0785 \\
\hline 13 & 1.1666 & 8.9311 & 0.3662 & 53 & 4.9512 & 20.7273 & 0.1175 \\
\hline 14 & 1.2439 & 9.2501 & 0.4865 & 54 & 5.1057 & 21.1255 & 0.1173 \\
\hline 15 & 1.3983 & 9.8678 & 0.4344 & 55 & 5.1829 & 21.3232 & 0.0781 \\
\hline 16 & 1.4756 & 10.1677 & 0.2606 & 56 & 5.2601 & 21.5200 & 0.0781 \\
\hline 17 & 1.5528 & 10.4620 & 0.3552 & 57 & 5.3374 & 21.7160 & 0.1171 \\
\hline 18 & 1.7073 & 11.0360 & 0.3247 & 58 & 5.4919 & 22.1055 & 0.1172 \\
\hline 19 & 1.7845 & 11.3162 & 0.1989 & 59 & 5.5691 & 22.2990 & 0.0783 \\
\hline 20 & 1.8617 & 11.5922 & 0.1876 & 60 & 5.6463 & 22.4918 & 0.0784 \\
\hline 21 & 1.9390 & 11.8644 & 0.2615 & 61 & 5.7236 & 22.6838 & 0.1178 \\
\hline 22 & 2.0935 & 12.3979 & 0.2442 & 62 & 5.8780 & 23.0655 & 0.1182 \\
\hline 23 & 2.1707 & 12.6597 & 0.1526 & 63 & 5.9553 & 23.2553 & 0.0790 \\
\hline 24 & 2.2479 & 12.9183 & 0.1459 & 64 & 6.0325 & 23.4443 & 0.1190 \\
\hline 25 & 2.3252 & 13.1740 & 0.1398 & 65 & 6.1870 & 23.8203 & 0.1195 \\
\hline 26 & 2.4024 & 13.4268 & 0.1342 & 66 & 6.2642 & 24.0073 & 0.0800 \\
\hline 27 & 2.4796 & 13.6769 & 0.1914 & 67 & 6.3415 & 24.1937 & 0.1206 \\
\hline 28 & 2.6341 & 14.1696 & 0.1826 & 68 & 6.4959 & 24.5644 & 0.1212 \\
\hline 29 & 2.7113 & 14.4124 & 0.1165 & 69 & 6.5732 & 24.7488 & 0.0813 \\
\hline 30 & 2.7886 & 14.6529 & 0.1678 & 70 & 6.6504 & 24.9327 & 0.0816 \\
\hline 31 & 2.9431 & 15.1275 & 0.1616 & 71 & 6.7276 & 25.1159 & 0.0820 \\
\hline 32 & 3.0203 & 15.3617 & 0.1040 & 72 & 6.8049 & 25.2985 & 0.1237 \\
\hline 33 & 3.0975 & 15.5940 & 0.1015 & 73 & 6.9593 & 25.6620 & 0.1244 \\
\hline 34 & 3.1748 & 15.8245 & 0.0992 & 74 & 7.0366 & 25.8429 & 0.0835 \\
\hline 35 & 3.2520 & 16.0532 & 0.1447 & 75 & 7.1138 & 26.0232 & 0.0839 \\
\hline 36 & 3.4065 & 16.5054 & 0.1410 & 76 & 7.1911 & 26.2030 & 0.1267 \\
\hline 37 & 3.4837 & 16.7290 & 0.0918 & 77 & 7.3455 & 26.5610 & 0.1276 \\
\hline 38 & 3.5609 & 16.9511 & 0.0903 & 78 & 7.4228 & 26.7392 & 0.0856 \\
\hline 39 & 3.6382 & 17.1717 & 0.0889 & 79 & 7.5000 & 26.9169 & 15.4377 \\
\hline 40 & 3.7154 & 17.3908 & 0.1309 & & & & \\
\hline
\end{tabular}




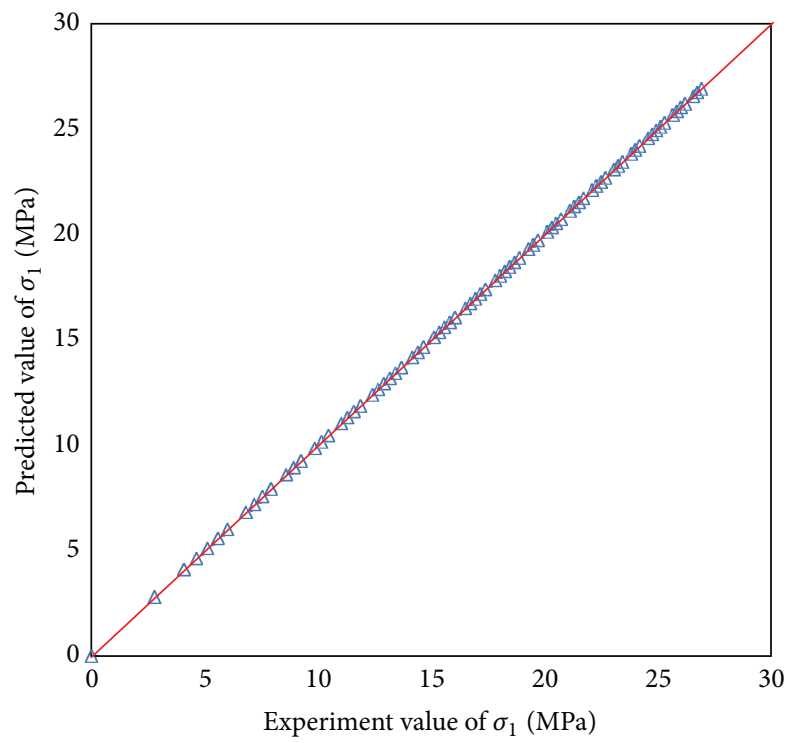

FIGURE 2: Comparison of major principal stress $\sigma_{1}$ between the experimental data and predicted value for training samples.

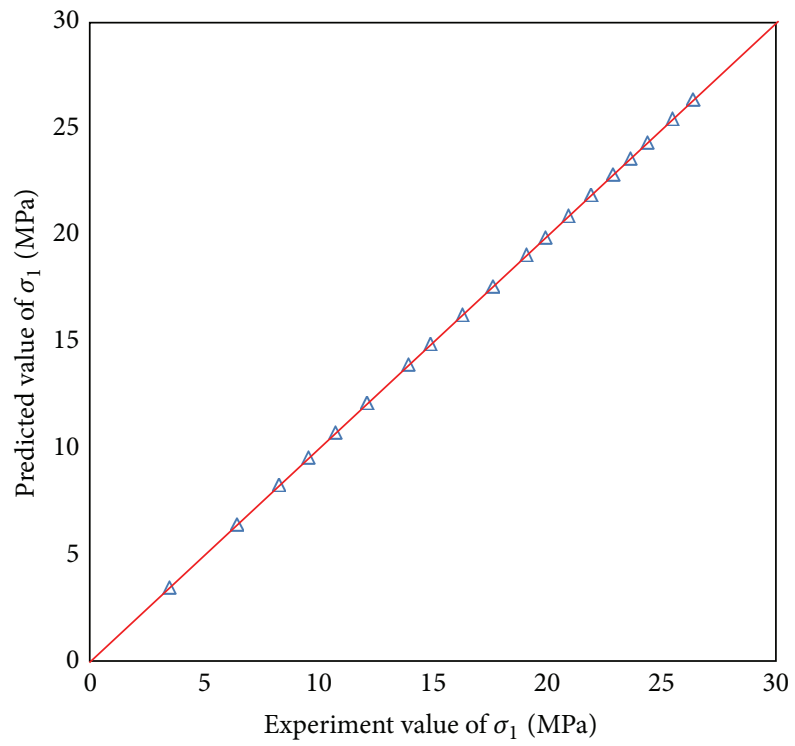

FIGURE 3: Comparison of major principal stress $\sigma_{1}$ between the experimental data and predicted value for testing samples.

\section{Numerical Experiment}

4.1. Matching the Experimental Data. In this work, the RBF kernel function was adopted for pattern analysis or recognition, with the following parameters: $\sigma=2$. The value of $b$ is 14.5061. The values of $\alpha_{k}$ are listed in Table 1. As in any other use of LSSVM, the SVM must be trained and tested; 98 data sets from triaxial compression tests, consisting of 79 training samples and 19 testing samples, were used as the experimental data in this study (seen in Table 1). Once the performance of the SVM model was satisfactory, it was used to represent the nonlinear relationship between rock properties and the mechanical behavior of the rock to establish the LSSVMbased rock failure criterion.

As shown in Figures 2 and 3, the predicted LSSVM values and experimental values of $\sigma_{1}$ were almost identical, indicating that the LSSVM-based failure criterion model effectively simulated the failure behavior. Figure 4 shows a comparison between the failure envelopes determined by the LSSVM, Mohr-Coulomb, and Hoek-Brown models and those 


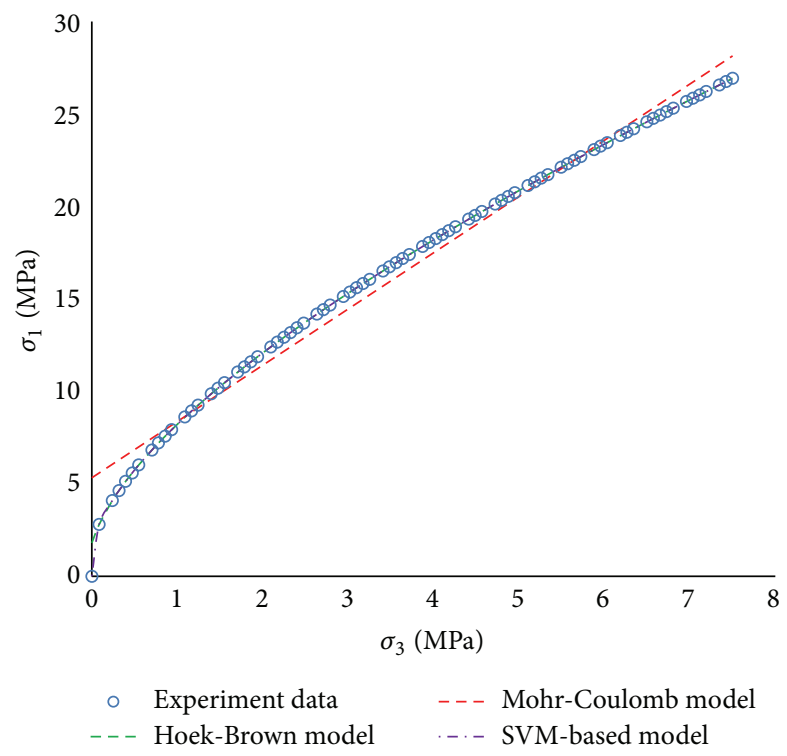

FIgURE 4: Comparison of failure envelopes for different rock failure criteria.

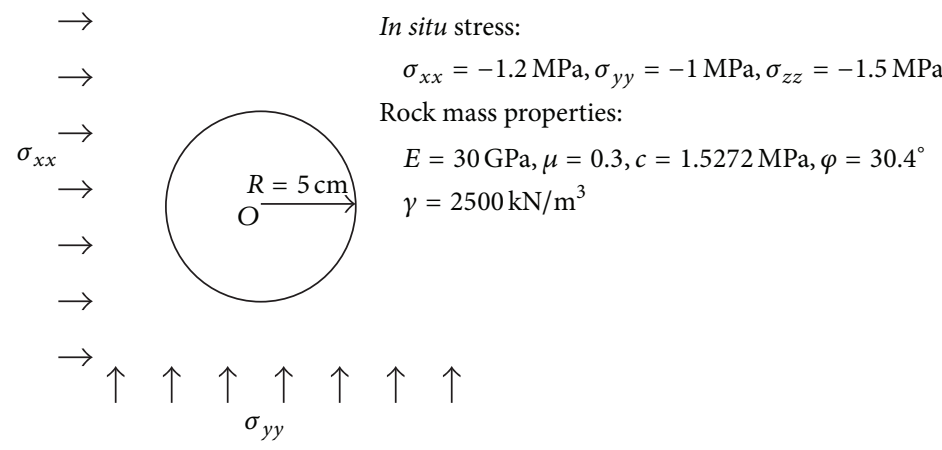

FIGURE 5: A circular tunnel model, stress condition, and rock mass properties.

from the experimental data. It can be seen from Figure 4 that $\sigma_{1}$ predicted by the LSSVM model agreed well both with the experimental data and the Hoek-Brown model at large stresses but differed a little from the Mohr-Coulomb model; however, $\sigma_{1}$ differed a little from the Hoek-Brown model at small stresses. These results indicate that the LSSVM-based rock failure criterion trained on experimental data predicts the failure behavior of rock with reasonable accuracy.

4.2. Numerical Analysis Using the LSSVM-Based Rock Failure Criterion. To verify the feasibility of the LSSVM-based rock failure criterion in numerical analysis, it was combined with FLAC3D modeling code to simulate the failure behavior of a $5 \mathrm{~m}$ radius circular rock tunnel as a hypothetical numerical case. An initial in situ stress and gravity was presupposed in the numerical model, and the experimental data from
Section 4.1 was used. The properties of the rock mass listed in Figure 5 are based on the Mohr-Coulomb model. The numerical model is built using FLAC3D together with the algorithm in Section 3. The horizontal displacements are almost the same as the value of Mohr-Coulomb by FLAC3D (seen in Figure 6). The stress of surrounding rock is in well agreement with the law of Mohr-Coulomb by FLAC3D (seen in Figure 7). The horizontal displacements and the horizontal, vertical, and shear stresses induced in the surrounding rock by the excavation show that the LSSVM model results were almost identical to those obtained by the Mohr-Coulomb model. The induced horizontal and vertical stresses calculated by the two models are also shown as contour plots in Figures 8 and 9. It shows the mechanical character of rock was presented by LSSVM-based rock failure criteria. Overall, the results show that the LSSVM-based rock failure criteria 


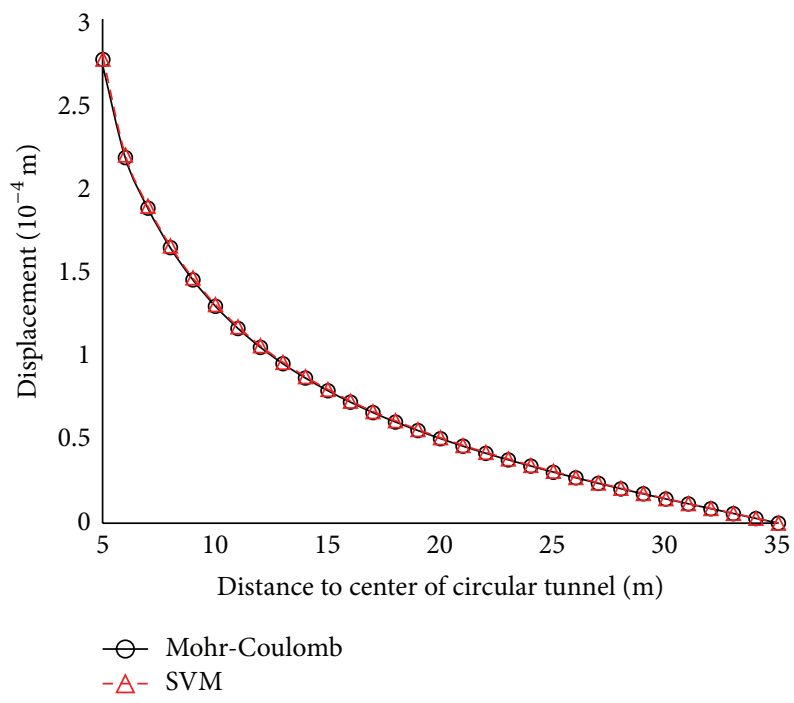

FIGURE 6: Comparison of surrounding rock displacement of tunnel obtained by LSSVM and Mohr-Coulomb model.

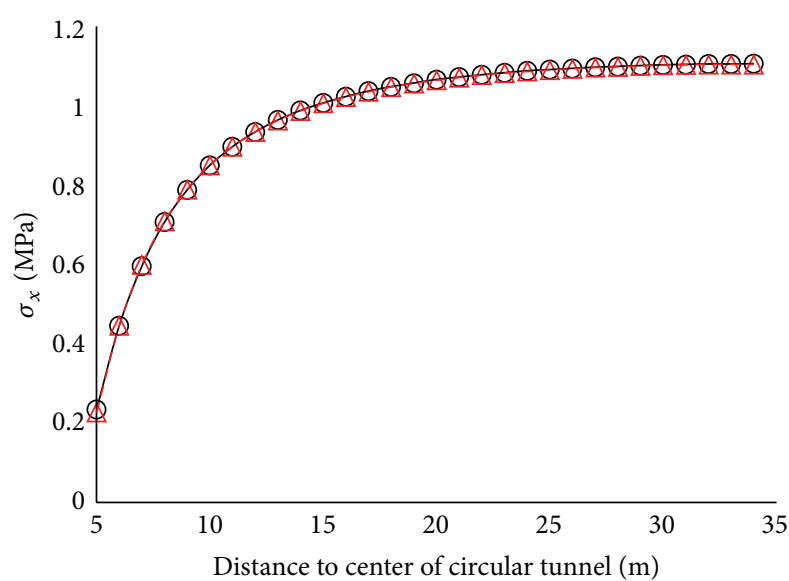

(a)

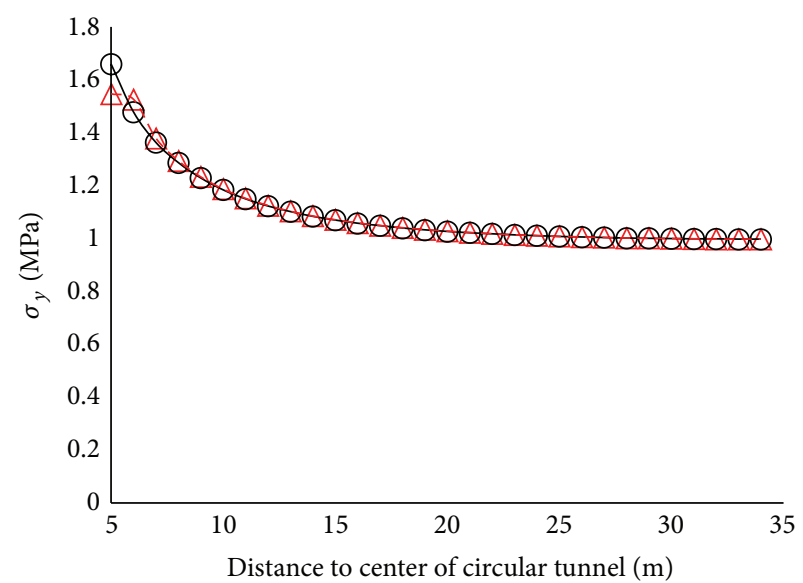

(b)

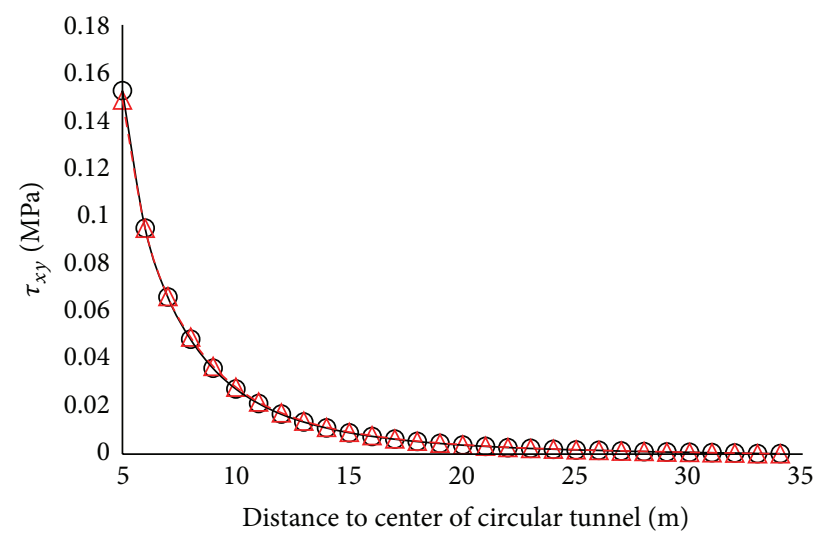

- Mohr-Coulomb $-A-$ SVM

(c)

FIGURE 7: Comparison of horizontal stress of tunnel obtained by LSSVM and Mohr-Coulomb model (a) $\sigma_{x}$, (b) $\sigma_{y}$, (c) $\sigma_{x y}$. 


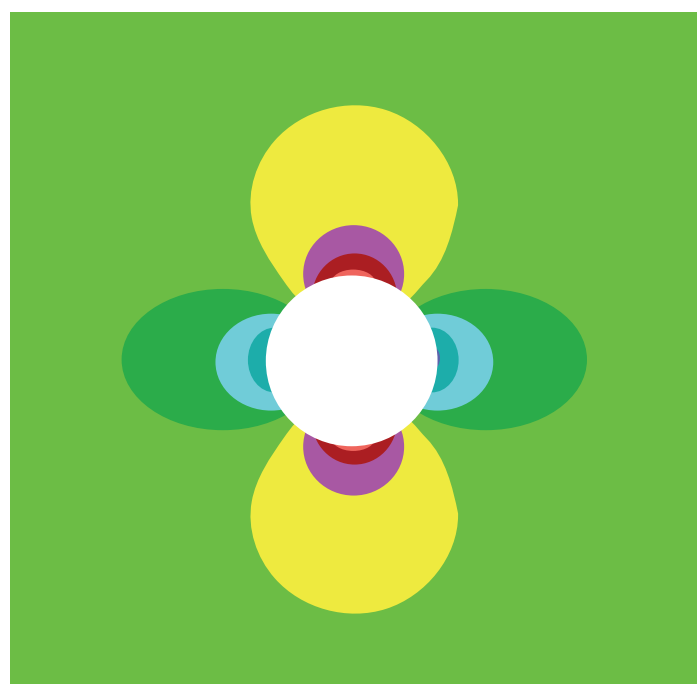

(a) Mohr-Coulomb model

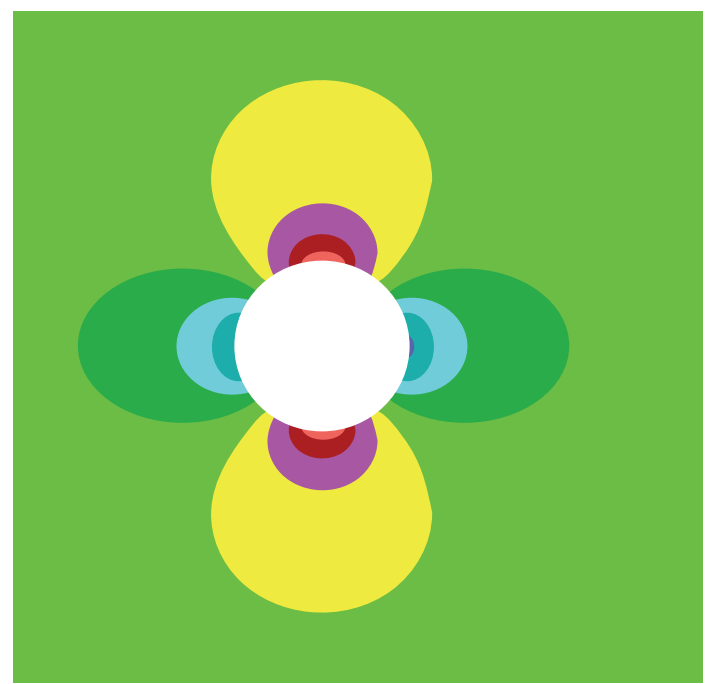

(b) LSSVM model

FIGURE 8: Comparison of horizontal stress contour in surrounding rock mass obtained by LSSVM and Mohr-Coulomb model.

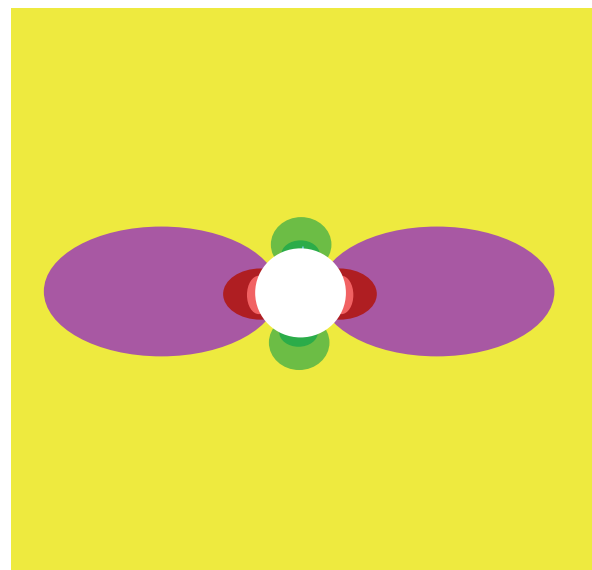

(a) Mohr-Coulomb model

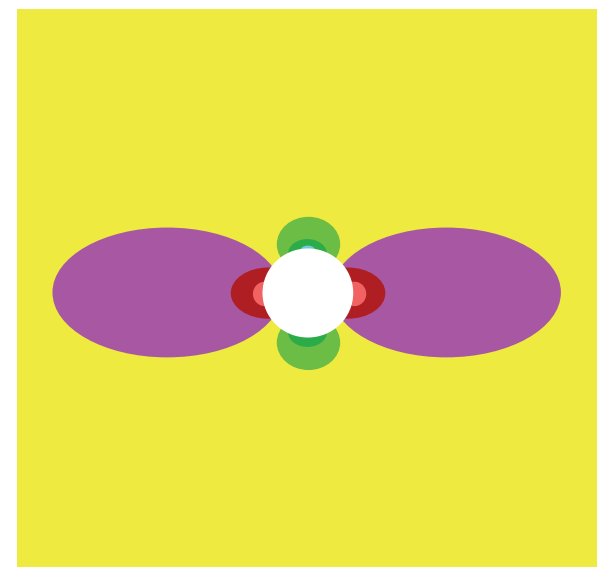

(b) LSSVM model

FIGURE 9: Comparison of vertical stress contour in surrounding rock mass obtained by LSSVM and Mohr-Coulomb model.

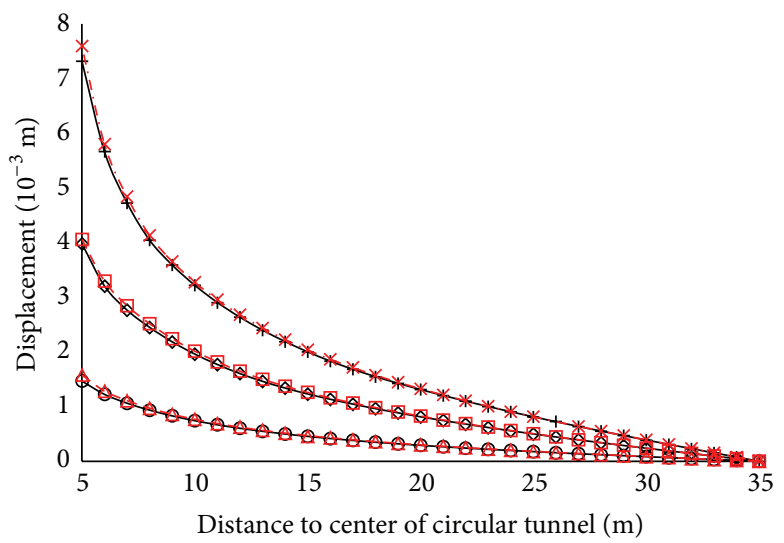

$$
\begin{aligned}
\multimap \mathrm{M}-\mathrm{C}: s_{y} & =5 \mathrm{MPa} & & -\triangle-\mathrm{SVM}: s_{y}=5 \mathrm{MPa} \\
\multimap \mathrm{M}-\mathrm{C}: s_{y} & =10 \mathrm{MPa} & & -\boxminus-\mathrm{SVM}: s_{y}=10 \mathrm{MPa} \\
\multimap \mathrm{M}-\mathrm{C}: s_{y} & =15 \mathrm{MPa} & & -\star-\mathrm{SVM}: s_{y}=15 \mathrm{MPa}
\end{aligned}
$$

FIGURE 10: Comparison of surrounding rock mass displacement obtained by LSSVM and Mohr-Coulomb model in different in situ stress level ( $s_{y}$ is the vertical in situ stress). 


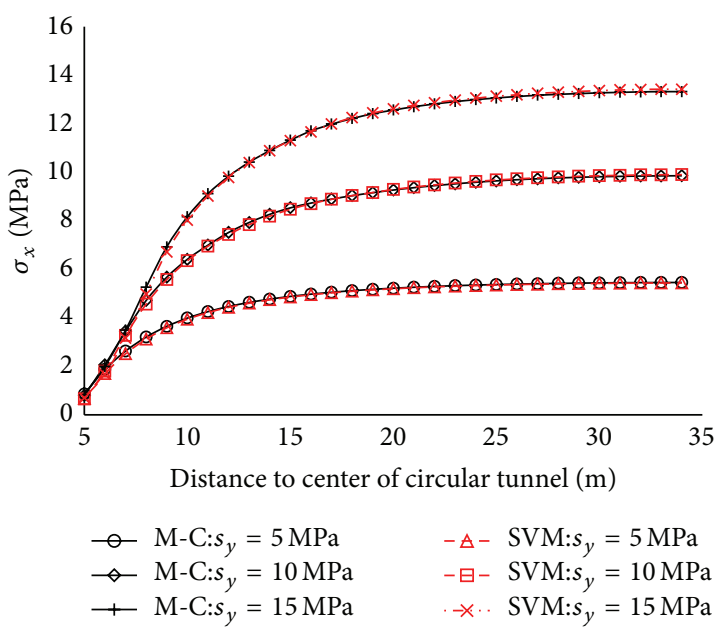

(a)

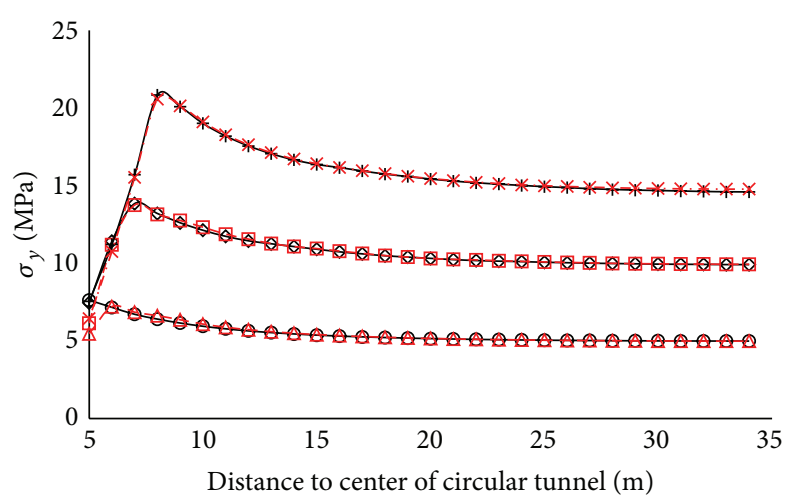

$$
\begin{array}{rlrl}
\multimap \mathrm{M}-\mathrm{C}: s_{y} & =5 \mathrm{MPa} & & -\triangle-\mathrm{SVM}: s_{y}=5 \mathrm{MPa} \\
\multimap \mathrm{M}-\mathrm{C}: s_{y}=10 \mathrm{MPa} & -\boxminus-\mathrm{SVM}: s_{y}=10 \mathrm{MPa} \\
+\mathrm{M}-\mathrm{C}: s_{y}=15 \mathrm{MPa} & -- \text { SVM:s } s_{y}=15 \mathrm{MPa}
\end{array}
$$

(b)

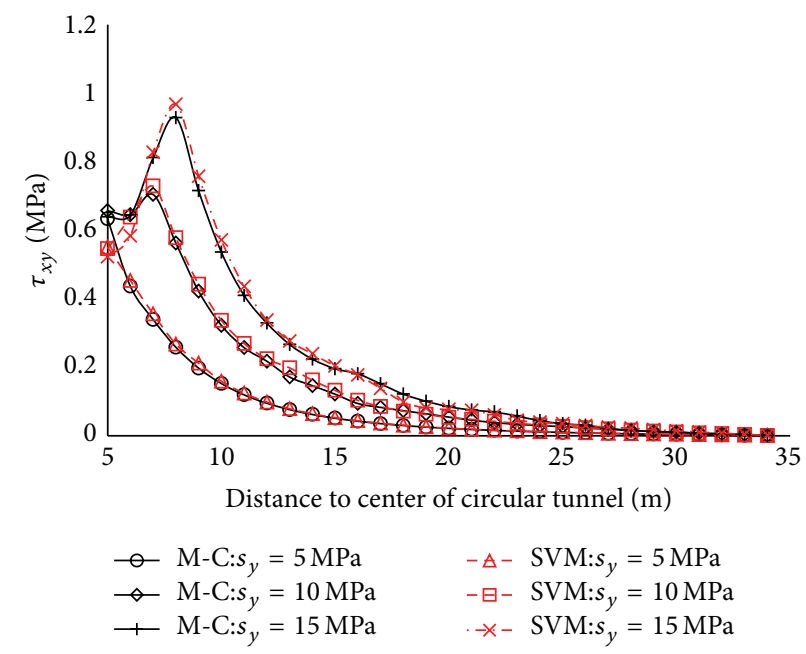

(c)

FIGURE 11: Comparison of surrounding rock stress of tunnel between LSSVM and Mohr-Coulomb model in different in situ stress level (a) $\sigma_{x},(\mathrm{~b}) \sigma_{y},(\mathrm{c}) \tau_{x y}\left(s_{y}\right.$ is the vertical in situ stress).

present well the mechanical behavior and character and can be used for numerical analysis.

To verify the LSSVM-based rock failure criterion for different initial in situ stress states, the circular tunnel was investigated at different vertical stress $\sigma_{y y}=5,10$, and $15 \mathrm{MPa}$ and corresponding horizontal stress $\sigma_{x x}=1.2 \sigma_{y y}$ in each case. The maximum error and maximum relative error of horizontal displacements are about 0.08 and $2.8 \%$, respectively. The maximum relative error of vertical stress and shear stress is about $18 \%$ at the beginning of excavation (seen Figure 11(b)) and then it will be less than 5\% with the excavation. Using the LSSVM and Mohr-Coulomb models, the calculated horizontal displacements in the rock surrounding the tunnel are shown in Figure 10 and the major principal stresses are shown in Figure 11. Those show it is feasible to combine LSSVM rock failure criterion with numerical analysis.
The displacements for both models agree well for the three initial in situ stress states (Figure 10), and the principal stresses are also similar for both models (Figure 11), with $\sigma_{y}$ and $\tau_{x y}$ showing small differences near the wall of tunnel. These results generally reflect the above results (in which $\sigma_{y y}=1 \mathrm{MPa}$.

The LSSVM and Hoek-Brown models were also compared. Figures 12-14 show the results for the same initial stress states as above, and it is seen that displacements in the surrounding rock agreed well with both the Hoek-Brown and Mohr-Coulomb results. Some small differences are evident in $\sigma_{x x}$ and $\tau_{x y}$ compared to the Mohr-Coulomb model, but the results are consistent with the Hoek-Brown model because, as shown in Figure 4, the LSSVM and Hoek-Brown failure envelopes are similar. Thus, the proposed failure criterion can be used in numerical analysis to effectively reflect the mechanical behavior of rock. 


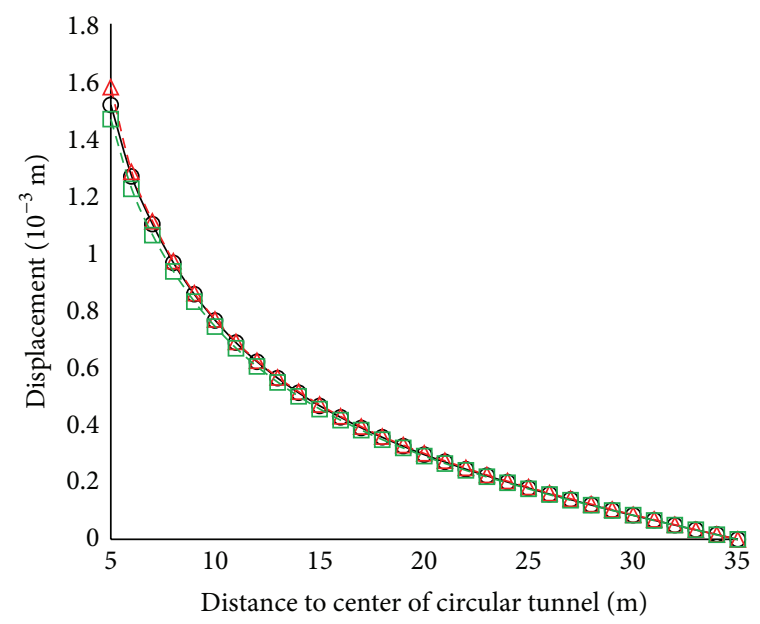

(a) Displacement

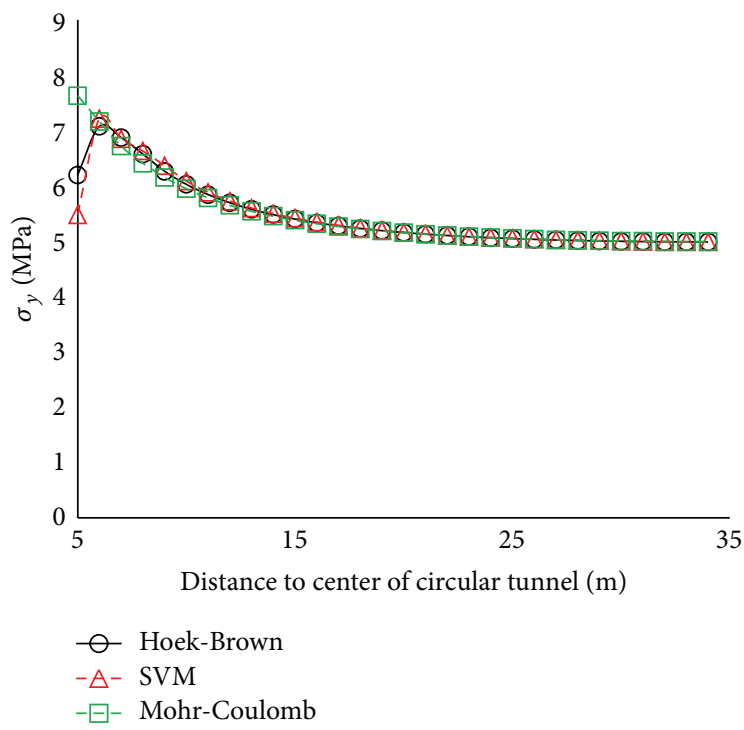

(c) $\sigma_{y}$

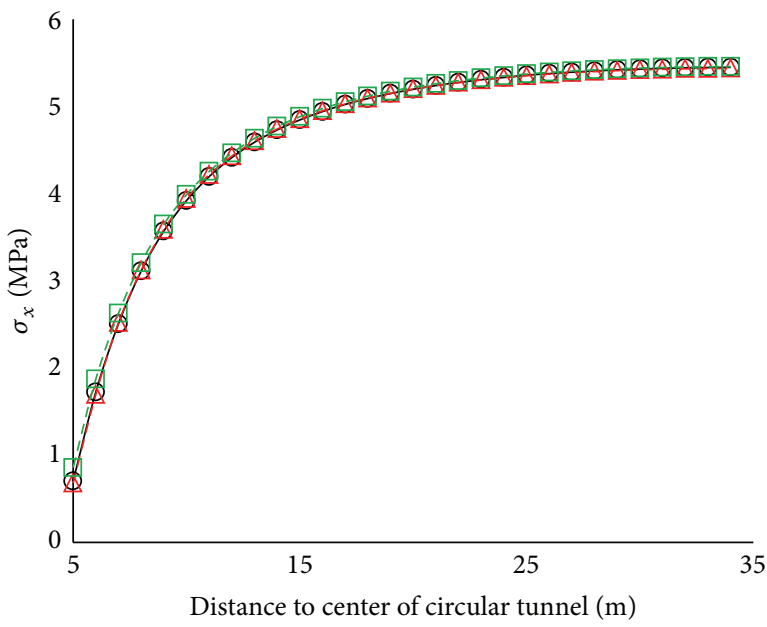

(b) $\sigma_{x}$

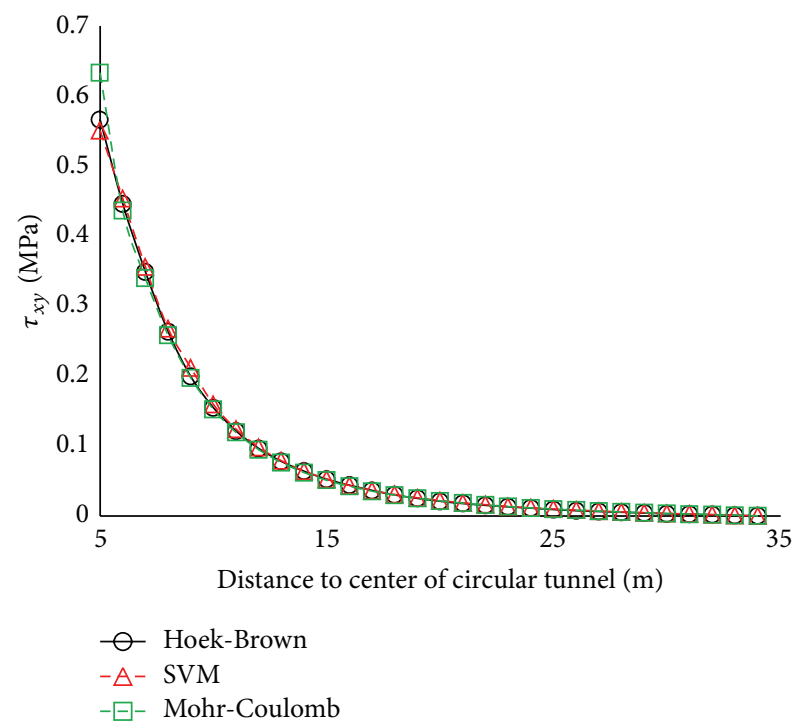

(d) $\tau_{x y}$

Figure 12: Displacement and stresses induced by excavation at $\sigma_{y}=5 \mathrm{MPa}$.

\section{Conclusions}

The results of comparisons between the proposed LSSVMbased rock failure criterion and the Mohr-Coulomb and Hoek-Brown criteria and experimental data demonstrated clearly that LSSVM provided an effective rock failure criterion for the purpose of numerical analysis. Comparisons of the displacements in the rock surrounding a circular tunnel from the LSSVM, Mohr-Coulomb and Hoek-Brown models, and experimental data showed that the LSSVM model mapped the nonlinear relationship between the mechanical properties of the rock and its failure behavior.

\section{List of Symbols}

$N$ : Number of samples

$R^{N}: \quad N$-dimensional vector space

$r$ : One-dimensional vector space

$x_{k}, y_{k}$ : Input and output of training samples

$\varphi(\cdot)$ : Nonlinear mapping in a higher-dimensional feature space

$w$ : Adjustable weight vector

b: $\quad$ Scalar threshold

$\gamma$ : $\quad$ Regularization parameter

$e_{k}$ : Error variable 


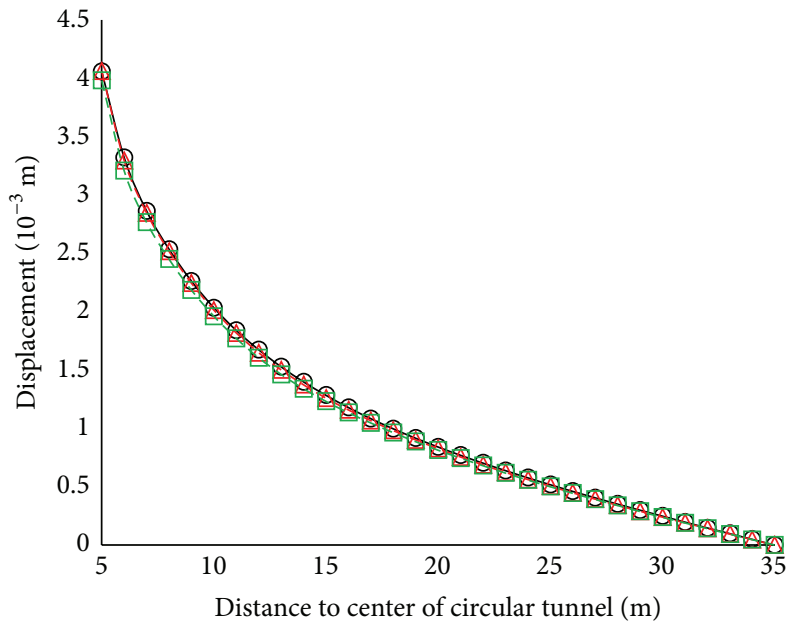

(a) Displacement

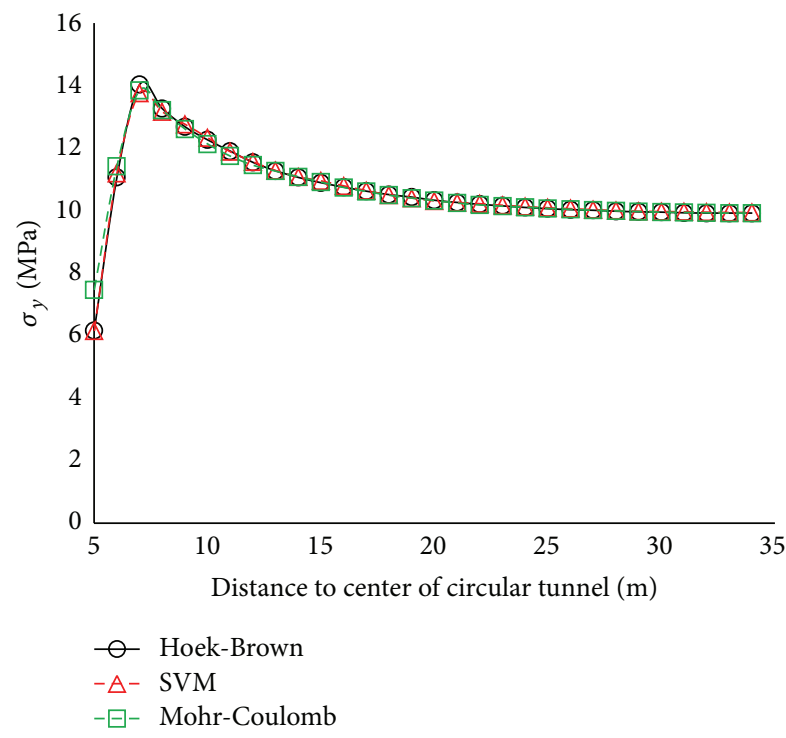

(c) $\sigma_{y}$

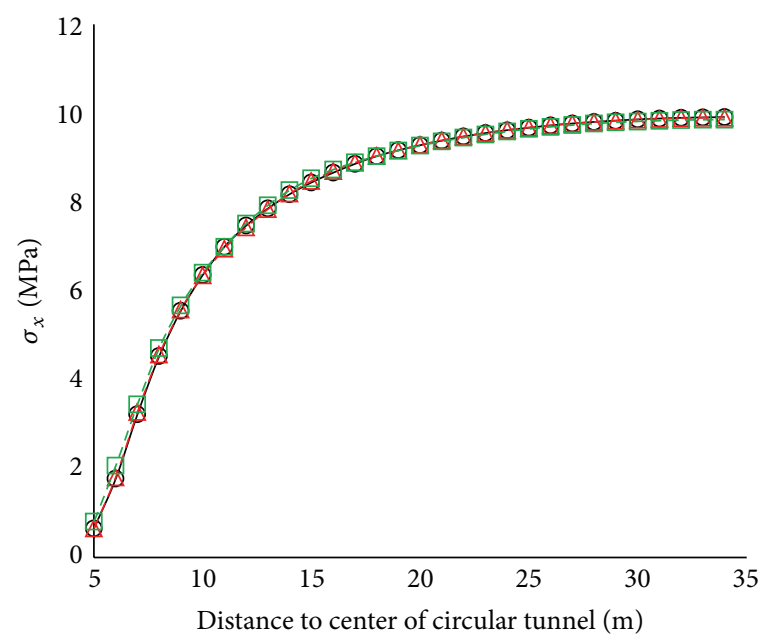

(b) $\sigma_{x}$

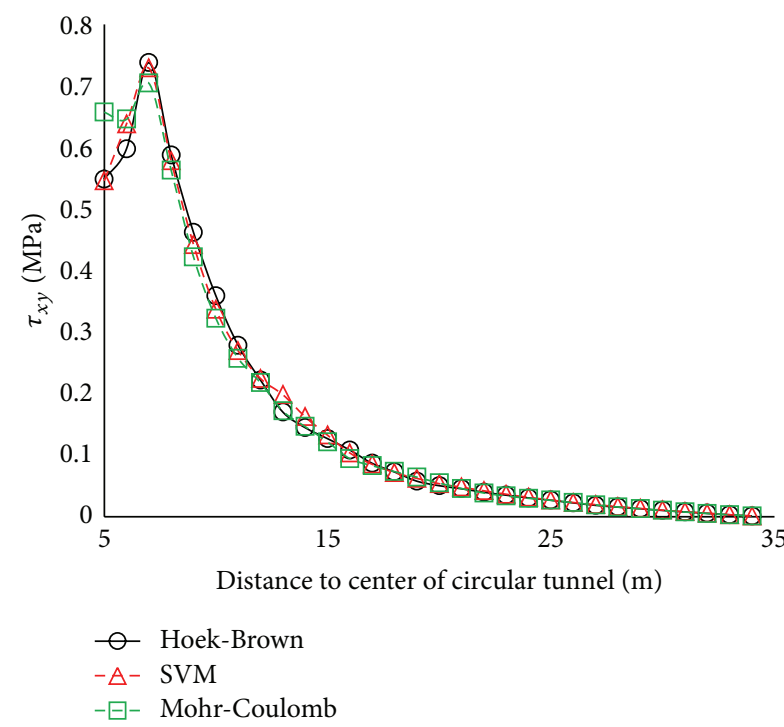

(d) $\tau_{x y}$

FIGURE 13: Displacement and stresses induced by excavation at $\sigma_{y}=10 \mathrm{MPa}$.

$\alpha_{k}$ : Lagrange multiplier

$k()$ : Kernel function

$\Phi: \quad$ Matrix of kernel function

l: $\quad 1 \times N$ matrix

$\sigma_{1}$ : Major principal stress

$\sigma_{3}$ : Minor principal stress

$\sigma_{y y}:$ Vertical in situ stress

$\sigma_{x x}$ : Horizontal in situ stress

$\sigma_{x}$ : Horizontal stress of surrounding rock mass

$\sigma_{y}$ : Vertical stress of surrounding rock mass

$\tau_{x y}:$ Shear stress

$\sigma_{3 k}$ : Experimental data

$c_{\mathrm{eq}}$ : Instantaneous values of cohesion $\varphi_{\mathrm{eq}}$ : Instantaneous values of friction angle

$\operatorname{SVM}($ ): LSSVM-based rock failure criteria

$\sigma$ : $\quad$ Parameter of RBF kernel function.

\section{Conflict of Interests}

The authors declare that there is no conflict of interests regarding the publication of this paper.

\section{Acknowledgments}

Support by the Program for Innovative Research Team (in Science and Technology) in University of Henan Province 


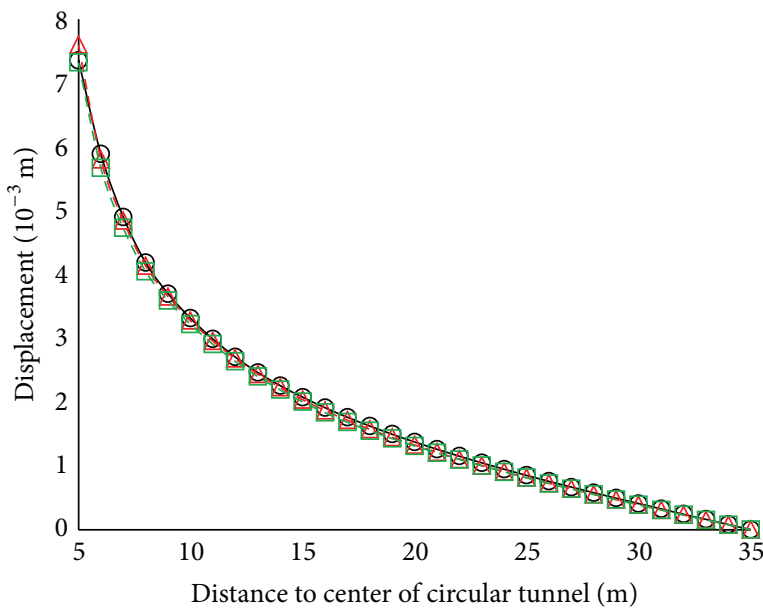

(a) Displacement

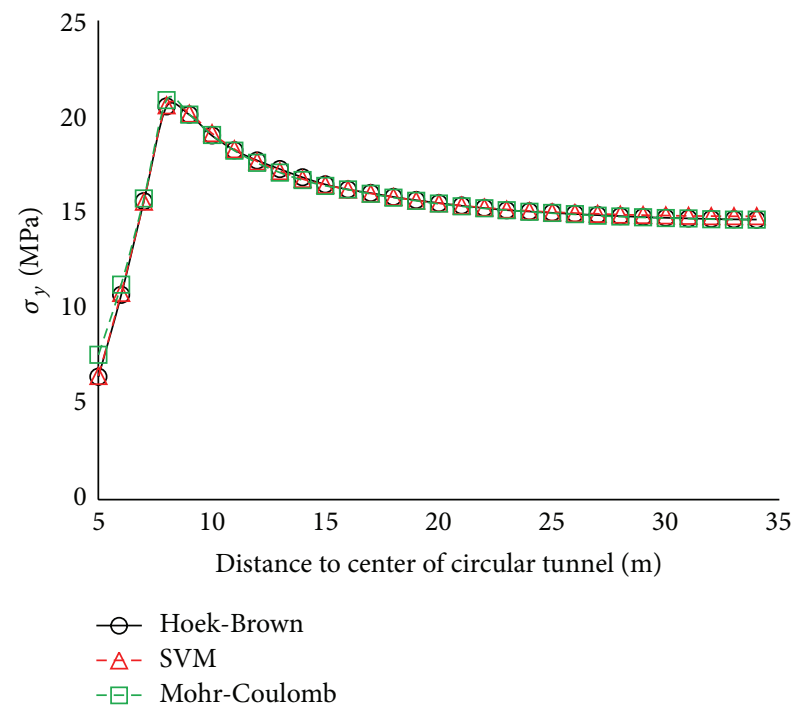

(c) $\sigma_{y}$

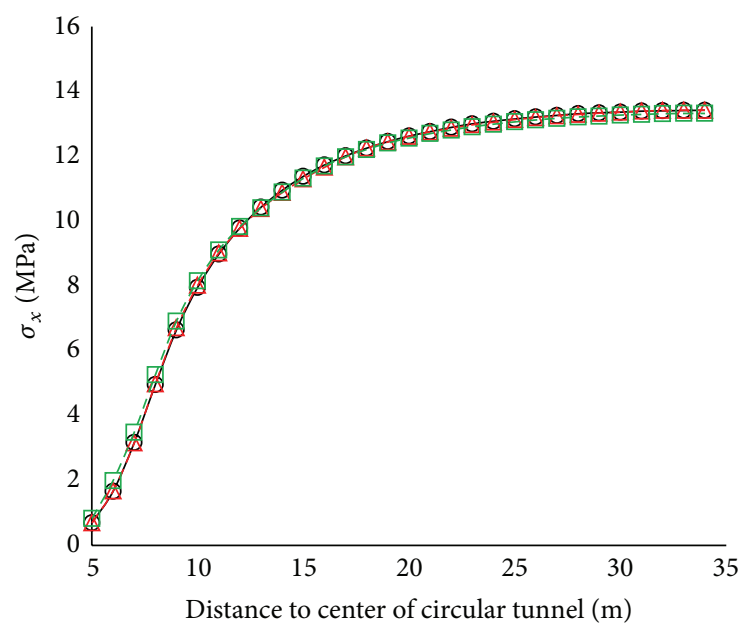

(b) $\sigma_{x}$

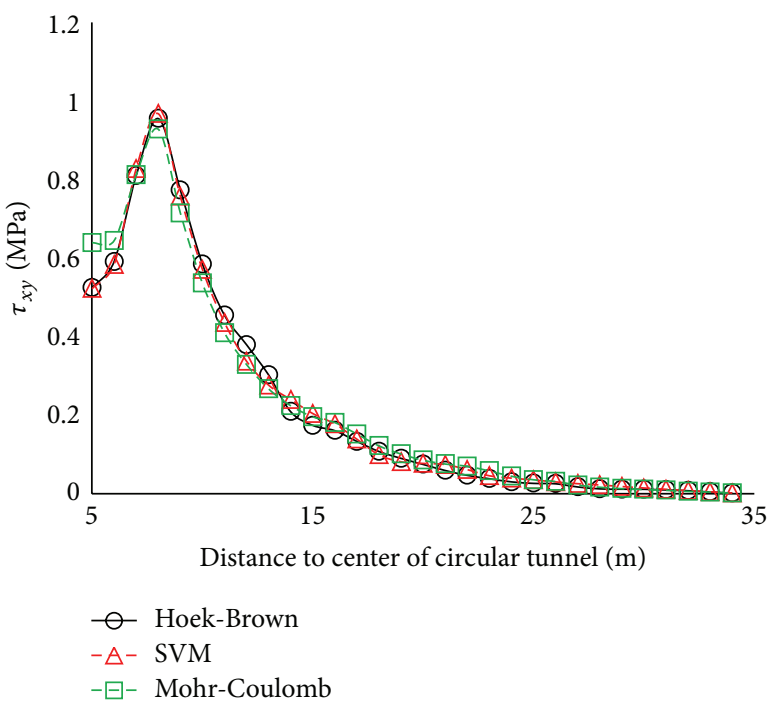

(d) $\tau_{x y}$

FIGURE 14: Displacement and stresses induced by excavation at $\sigma_{y}=15 \mathrm{MPa}$.

(no. 15IRTSTHN029) and National Fund of Science in China (nos. 51104057, 41172244) are gratefully acknowledged.

\section{References}

[1] R. Ulusay and J. A. Hudson, "Suggested methods for rock failure criteria: general introduction," Rock Mechanics and Rock Engineering, vol. 45, no. 6, p. 971, 2012.

[2] C. Fairhurst, "On the validity of the 'Brazilian' test for brittle materials," International Journal of Rock Mechanics and Mining Sciences \& Geomechanics Abstracts, vol. 1, no. 4, pp. 535-546, 1964.

[3] D. W. Hobbs, "The strength and the stress-strain characteristics of coal in triaxial compression," The Journal of Geology, vol. 72, no. 2, pp. 214-231, 1964.

[4] S. A. F. Murrell, "The effect of triaxial stress systems on the strength of rock at atmospheric temperature," International
Journal of Rock Mechanics and Mining Sciences, vol. 3, pp. 11-43, 1965.

[5] J. A. Franklin, "Triaxial strength of rock materials," Rock Mechanics Felsmechanik Mécanique des Roches, vol. 3, no. 2, pp. 86-98, 1971.

[6] Z. T. Bieniawski, "Estimating the strength of rock materials," Journal of The South African Institute of Mining and Metallurgy, vol. 74, no. 8, pp. 312-320, 1974.

[7] E. Hoek and E. T. Brown, Underground Excavations in Rock, Institution of Mining \& Metallurgy, London, UK, 1980.

[8] T. Ramamurthy, G. V. Rao, and K. Rao, "A strength criterion for rocks," in Proceedings of the Indian Geotechnical Conference, pp. 59-64, Roorkee, India, 1985.

[9] I. W. Johnston, "Strength of intact geomechanical materials," Journal of Geotechnical Engineering, vol. 111, no. 6, pp. 730-749, 1985. 
[10] P. R. Sheorey, A. K. Biswas, and V. D. Choubey, "An empirical failure criterion for rocks and jointed rock masses," Engineering Geology, vol. 26, no. 2, pp. 141-159, 1989.

[11] N. Yoshida, N. R. Morgenstern, and D. H. Chan, "A failure criterion for stiff soils and rocks exhibiting softening," Canadian Geotechnical Journal, vol. 27, no. 2, pp. 195-202, 1990.

[12] J. F. Labuz and A. Zang, "Mohr-Coulomb failure criterion," Rock Mechanics and Rock Engineering, vol. 45, no. 6, pp. 975-979, 2012.

[13] E. Eberhardt, "The Hoek-Brown failure criterion," Rock Mechanics and Rock Engineering, vol. 45, no. 6, pp. 981-988, 2012.

[14] F. Meulenkamp and M. A. Grima, "Application of neural networks for the prediction of the unconfined compressive strength from Equotip hardness," International Journal of Rock Mechanics and Mining Sciences, vol. 36, no. 1, pp. 29-39, 1999.

[15] V. K. Singh, D. Singh, and T. N. Singh, "Prediction of strength properties of some schistose rocks from petrographic properties using artificial neural networks," International Journal of Rock Mechanics and Mining Sciences, vol. 38, no. 2, pp. 269-284, 2001.

[16] H. Çanakci and M. Pala, "Tensile strength of basalt from a neural network," Engineering Geology, vol. 94, no. 1-2, pp. 1018, 2007.

[17] B. Tiryaki, "Predicting intact rock strength for mechanical excavation using multivariate statistics, artificial neural networks, and regression trees," Engineering Geology, vol. 99, no. 1-2, pp. 51-60, 2008.

[18] K. Zorlu, C. Gokceoglu, F. Ocakoglu, H. A. Nefeslioglu, and S. Acikalin, "Prediction of uniaxial compressive strength of sandstones using petrography-based models," Engineering Geology, vol. 96, no. 3-4, pp. 141-158, 2008.

[19] H. Rafiai and A. Jafari, "Artificial neural networks as a basis for new generation of rock failure criteria," International Journal of Rock Mechanics and Mining Sciences, vol. 48, no. 7, pp. 1153-1159, 2011.

[20] H. Rafiai and A. Jafari, "Implementation of ANN-based rock failure criteria in numerical simulations," in Proceedings of the 12th International Congress on Rock Mechanics of the International Society for Rock Mechanics (ISRM '11), pp. 501-506, Beijing, China, October 2011.

[21] H.-B. Zhao, "Slope reliability analysis using a support vector machine," Computers and Geotechnics, vol. 35, no. 3, pp. 459467, 2008.

[22] H.-B. Zhao and S. Yin, "Geomechanical parameters identification by particle swarm optimization and support vector machine," Applied Mathematical Modelling, vol. 33, no. 10, pp. 3997-4012, 2009.

[23] H.-B. Zhao and S. Yin, "A CPSO-SVM model for ultimate bearing capacity determination," Marine Georesources and Geotechnology, vol. 28, no. 1, pp. 64-75, 2010.

[24] J. A. K. Suykens and J. Vandewalle, "Least squares support vector machine classifiers," Neural Processing Letters, vol. 9, no. 3, pp. 293-300, 1999. 


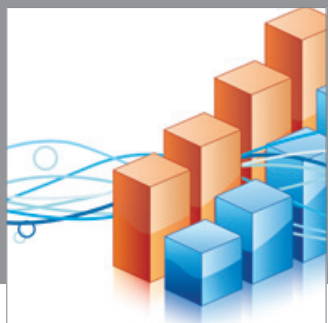

Advances in

Operations Research

mansans

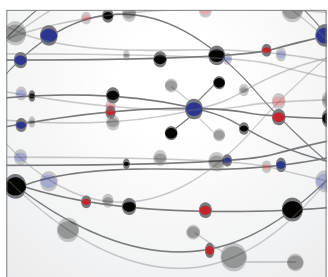

The Scientific World Journal
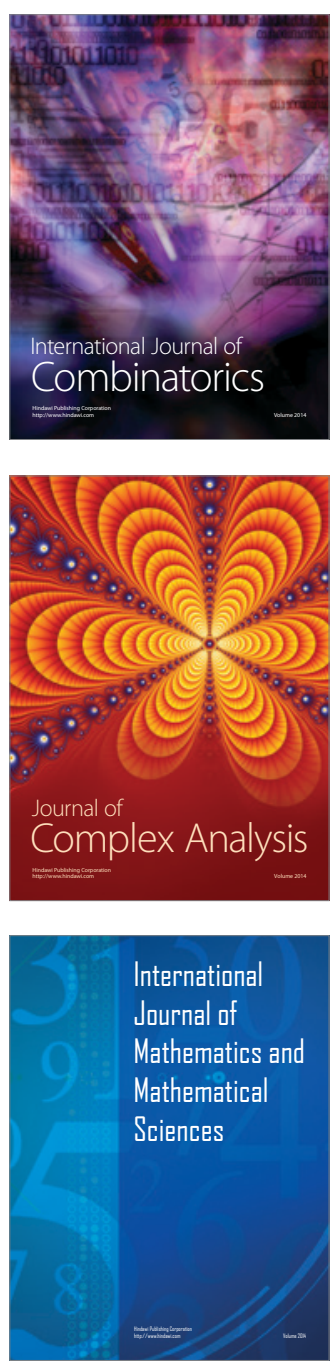
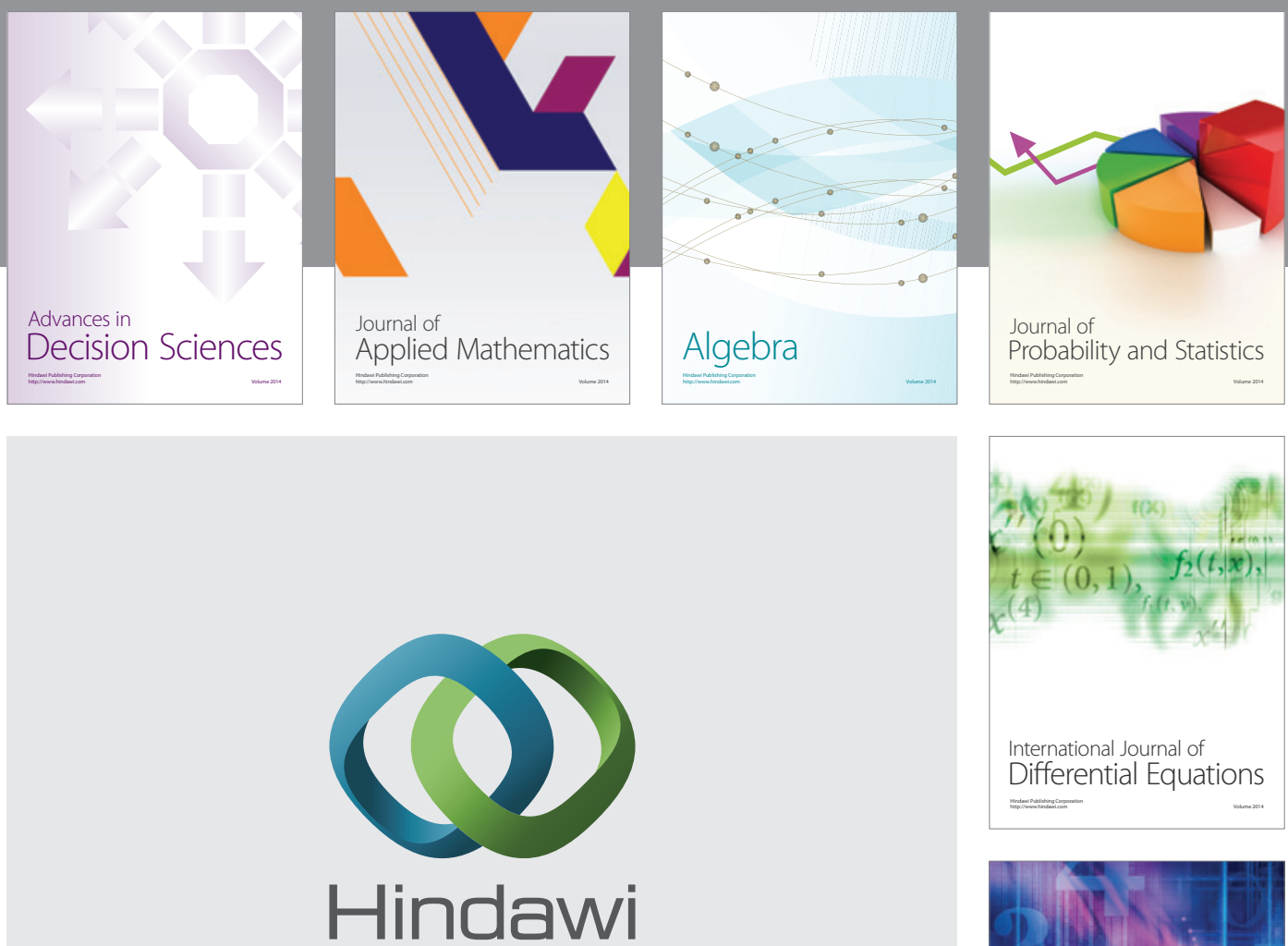

Submit your manuscripts at http://www.hindawi.com
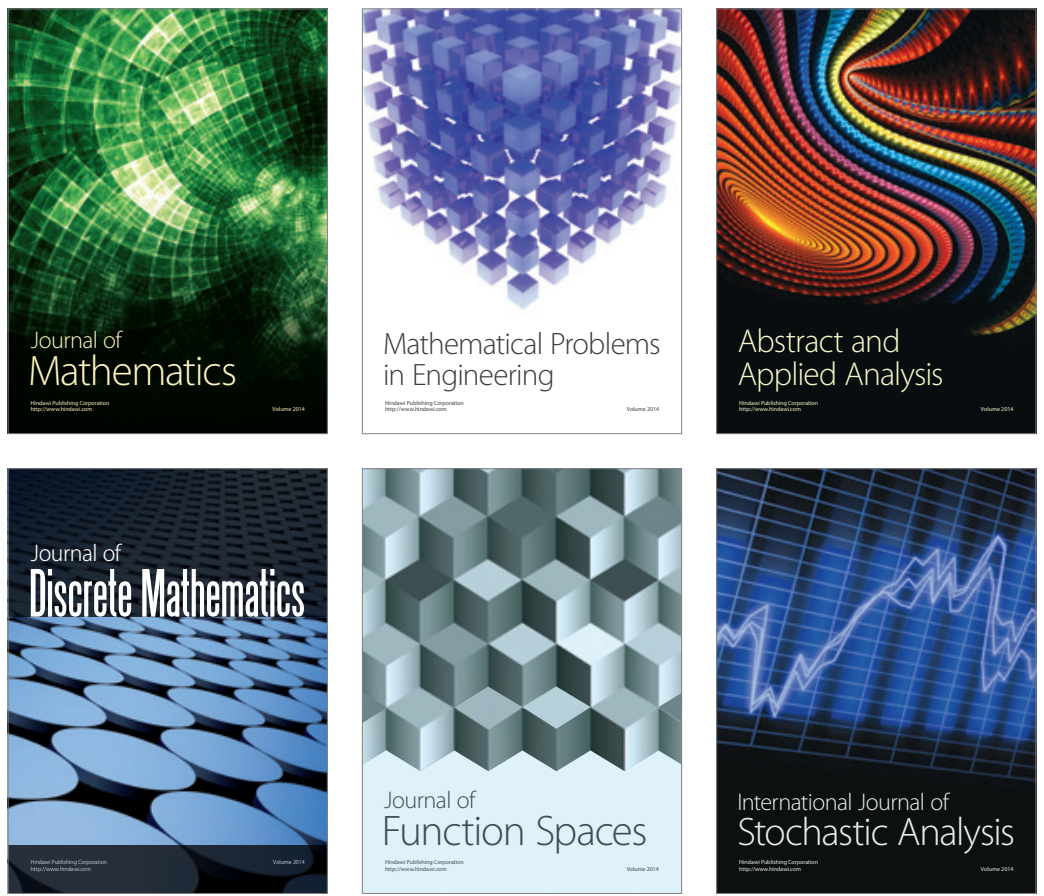

Journal of

Function Spaces

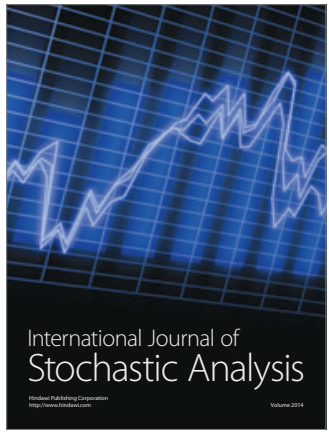

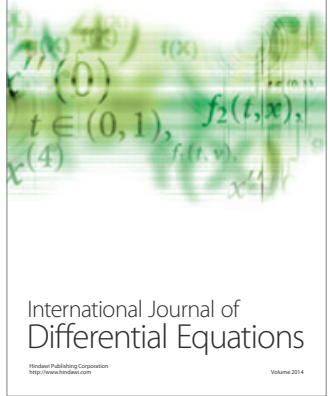
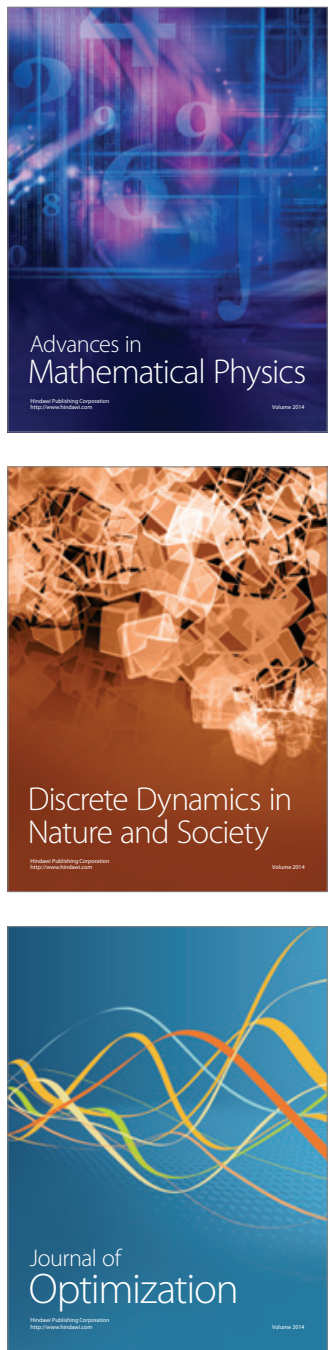